\title{
A Semantic Analysis of Negative Concord
}

\author{
Ton van der Wouden and Frans Zwarts
}

$\mathrm{BCN}$, University of Groningen

\section{Two types of negative concord}

It is not uncommon in natural languages that negation seems to behave in an illogical manner. ${ }^{1}$ The general term for the many cases where multiple occurrences of morphologically negative constituents express a single semantic negation is negative concord (Labov 1979).

Negative concord may take either of two forms: 1. the negative feature is 'spread' or distributed over any number of indefinite expressions within its scope; 2 . a distinguished negative element shows up in all sentences that contain a negative expression. After den Besten (1986), we call these two types of concord negative spread and negative doubling, ${ }^{2}$ respectively. Languages may show either of them, none, or both. Patterns typical of negative spread and negative doubling are exemplified in (1) and (2) below, combinations of them are given in (3).

(1) a. Nobody said nothing to nobody (NS English: Ladusaw (1991))

b. Personne a rien dit (Spoken French)

Nobody has nothing said

'Nobody said anything'

c. Valère ging nooit nieverst noatoe (West Flemish: Haegeman and Zanuttini (1990))

V. went never nowhere to

'V. never went anywhere'

(2) a. Je n' ai vu personne (standard French)

I not-have seen nobody

'I haven't seen anybody'

b. Valère en-klaapt tegen geen mens (West Flemish: Haegeman and Zanuttini (1990))

V. not-talks to no person

' $V$ doesn't talk to anybody'

\footnotetext{
${ }^{1}$ An earlier version of this paper was published as van der Wouden and Zwarts (1992). The research reported on is carried out within the framework of the PIONIER project 'Reflections of Logical Patrems in Language Struenre and Language Use', which is financed by NWO, the Dutch Organisabion for Scientific Reseanch, and the University of Groningen. We wish to thank the audience at SALT III and Brigitte Kampers-Manhe, Arie Molendijk. Veronique Remus, Sylvie Nison, Karin Robbers and especially Jack Hoeksema for discussion of data and comments on earlier versions.

${ }^{2}$ Negative doubling should be carefully distingaished from double negation: the latter term refers to two logical negations in the semantics, whereas the former applies to one logical negation.
}

(C) 1993 by Ton van der Wouden and Frans Zwarts

Utpal Lahiri and Adam Wyner (eds.), SALT III, 202-219, Ithaca, N.Y.: Cornell University. 
c. Hulle het nooit gesing nie (Afrikaans: den Besten (1986))

They have never sung not

'They have never sung'

(3) a. Personne n'a rien dit (French)

Nobody not-has nothing said

'Nobody said anything'

b. Valère en-ging nooit nieverst noatoe (West Flemish: Haegeman and Zanuttini (1990))

V. not-went never nowhere to

'V. never went anywhere'

We assume that both types of negative concord involve one (and only one) triggering element and one (or more) concordant or doubling element(s). We will return to the problem of deciding which is which in spread structures shortly.

By definition, no such problem exists in doubling constructions. In French, the doubling element is ne or (before vowels) $n(2 a)$ ), in West Flemish it is $e^{3}$ (2b), and in Afrikaans it is nie or (in spoken language) ie (2c). Note that the position of the doubling element may vary, even between closely related languages: in West Flemish (as in French) it cliticizes onto the finite verb, whereas it is sentence-final in Afrikaans. Discussion of this variation is beyond the scope of the present paper.

\section{The contexts of negative concord}

The term 'negative concord' is a misnomer. In certain languages, it may be triggered by elements and constructions that are not (overtly) negative, such as the English adverb hardly in (4a) and the Italian comparative in (4b).

(4) a. There was hardly no money nor hardly no bread (Cockney: Seuren (1991))

b. Maria è piú intelligente di quanto non sia Carlo (Italian: Napoli and Nespor (1976))

Maria is more intelligent than Carlo not is

Very weak negative expressions may also trigger the effect:

(5) a. Presque personne n'a vu l'accident

Almost nobody not-has seen the-accident

'Almost nobody saw the accident'

b. Nie alle bestuurders sal dit in die stadsverkeer waag nie (Afrikaans: Ponelis (1985))

Not all drivers will this in the city traffic dare not

\footnotetext{
${ }^{3}$ This en occurred in many earlier Dutch dialects: cf. Stoet (1923).
} 
Note that there is a strong parallel with polarity phenomena in this respect: we find negative polarity items in certain comparative constructions, after weak negative expressions, and in the scope of adverbs such as hardly as well.

(6) a. Sharon is lovelier than anyone expected her to be

b. Presque personne n'a fait le moindre bruit Almost nobody not-has made the least noise

c. There was hardly any money, and hardly any hope

In the seminal work of Ladusaw (1979), the semantic property of downward monotonicity was demonstrated to be the crucial factor in triggering negative polarity in English (normal negation being only one of the many operators possessing this property). Zwarts (1981) and Hoeksema (1983) have shown that certain negative polarity items (NPIs) in Dutch only occur with a subset of the downward monotonic operators, viz. the anti-additive ones (comparable generalizations hold for English (van der Wouden 1992)). The relevant definitions are given below:

(7) Definition $A$ functor $f$ is downward monotonic iff $f(X$ or $Y) \rightarrow f(X)$ and $f(Y)$

(8) Definition $A$ functor $f$ is anti-additive iff $f(X$ or $Y) \leftrightarrow f(X)$ and $f(Y)$

These functional properties are by no means restricted to one syntactic class or one language. For instance, the noun phrases presque personne and niet alle bestuwders and the adverb handly are all downward monotonic, the preposition without and the sentential comparative are anti-additive (Hoeksema 1983).

\section{Context-sensitive semantics}

Consider a sentence with an even number of negative lexical elements in a negative concord language such as (spoken) French.

(9) a. Personne a rien vu (spoken French)

Nobody has nothing seen

'Nobody saw anything'

b. J'ai rien vu (spoken French)

I-have nothing seen

'I didn't see anything'

If negation were to behave logically, sentence (9a) would mean 'everybody saw something', with the two negations canceling each other. However, the sentence means 'Nobody saw anything'. We cannot simply claim that rien means "anything", since it cannot mean anything else than "nothing" in (9b). What can we say, then, about the semantics of lexical elements such as riem, that sometimes means 
"nothing", and "anything" at other moments, given that we want to adhere to a compositional semantics, i.e., to the assumption that the meaning of the whole is a function of the meaning of its parts and the way they are combined?

Assume that the assignment of semantic values may be context-sensitive. By this we mean that the semantic contribution of a lexical element may be dependent on the meaning of the construction it is part of. If this is a valid move, then we have a way to implement our intuition that $n-$ words denote an existential quantifier when they are in the scope of a negative element and a universal negative quantifier in all other cases. In terms of the theory of quaternality, what this means is that the denotation of a negative word can vary between an existential quantifier and its complement. 4

Can we find arguments that justify such an extension of the Fregean principle of compositionality? We think the answer should be affirmative. To begin with, it has been suggested in the literature (Keenan 1974, Partee 1984) that the polysemy of adjectives such as red and flat in combinations like the ones below can (and should) be implemented by adopting a disjunctive meaning function for the adjective, along the lines of (11). ${ }^{5}$ This meaning function would then associate the form red with various semantic values, depending on the noun being modified.

(10) a. red grapefruit, red army, red carpet

b. flat tire, flat beer, flat surface

$$
f(x)=\left\{\begin{array}{l}
\ldots \text { if } P_{1}(x) \\
\ldots \text { if } P_{2}(x) \\
\ldots \\
\ldots \text { otherwise }
\end{array}\right.
$$

Secondly, verb meanings may differ with respect to the environment in which they occur (Pustejovsky 1989):
a. to bake a cake
b. to bake a potato

(13) a. Mary hammered the metal

b. Mary hammered the metal flat

(14) a. Mary ran yesterday

b. Mary ran to the store yesterday

It has been proposed in the literature (e.g. Atkins, Kegl and Levin (1988)) that verbs such as bake are ambiguous between a creation verb, as in (12a), and a change

\footnotetext{
${ }^{4}$ The theory of quaremality and the associated notions of duality, contraduality, and complementation are discussed in Zwarts (1991).

${ }^{5}$ Note that the combinations are mone or less fixed, i.e. collocational, which guarantees (one would hope) that the number of different meanings atributed to red and fiat will be finite.
} 
of state verb, as in (12b). In (12a), there is no cake before the act of baking: it comes into being by the act of baking. On the other hand, in (12b) a potato exists both before and after the baking, the only difference being the change from unbaked into baked. Likewise, it has been claimed (Dowty 1979) that the verb hamoner should have two lexical representations, one for its resultative usage (13b), and one for the other (13a). Finally, verbs of the nun-ype have been described as being polysemous (between the meanings "move by running" (14a) and "go to by means of running" (14b)) as well (Talmy 1985).

Pustejovsky advocates an alternative view. He proposes to leave the aspect type of verbs underspecified, and to make them sensitive to properties of their argument(s) instead. For example, a word such as cake, that refers to a thing that is an artifact, inherits in the lexicon certain general features that are typical for artifacts, such as the property of being able to be created. If it is combined with a verb like bake that is aspectually unspecified it triggers a creation reading for the verb. On the other hand, words like potato that are not lexically specified as artifacts are not able to trigger this reading. In those cases, only the change of state reading is available. A comparable approach is advocated for the other types of verbs discussed. ${ }^{6}$

Thirdly, so-called negative polarity idioms, such as lift a finger and hold $a$ candle get their idiomatic reading only in contexts such as (15). Earlier we characterized these contexts in semantic terms as downward monotonic. Note, however, that most of these negative polarity idioms, e.g. lift a finger and hold a candle, also occur in grammatical sentences which do not provide a downward monotonic context (16).

(15) a. Emie wouldn't lift a finger to help a lady in distress

b. His proposal doesn't hold a candle against ours

(16) a. Emie lifted a finger and the whole orchestra started to play

b. John would like to hold a candle against ours in order to light it

In a sense it is therefore unjustified to call the strings under discussion negative polarity items, if we understand this term in the usual way, i.e. as denoting elements that occur only in negation-like environments. Therefore, it might be better to reanalyze this phenomenon as another case of context-sensitive meaning attribution. The expression lift a finger would then be polysemous in much the same way that the adjective red is: it would mean 'do nothing' (the 'idiomatic' meaning) when construed in the scope of a downward monotonic operator, and 'move a certain body

\footnotetext{
${ }^{6}$ This, of course, calls for a richer lexical representation. Pusrejovsty (1989)"I suggest that there is a system of relations that characterizes the semantics of nominals, very much like the argument structure of a verb. I call this the Qualia Structure [... ]. Essentially, the qualia structure of a noun detemines its meaning as much as the list of arguments determines a verb's meaning." [...] "When we combine the qualia structure of a NP with the agument suructure of a verb, we begin to see a richer notion of compositionality emenging".
} 
part in upward direction' (the 'literal' meaning) elsewhere. ${ }^{7}$ Note that this instance of context-sensitive assignment of semantic values is sensitive to the same type of contextual properties as the negative concord cases, viz the family of downward monotonic functions.

Therefore, given that the concept of context-sensitive semantics is not new, and that a comparable mechanism turns up elsewhere, we suggest the following:

(17) Hypothesis 1 Negative doubling involves the formation of a marked verbal projection by means of a designated element that has the morphological shape of a negative, but denotes the identity function. This designated element itself must be licensed by an expression with the appropriate semantic properties. Though these properties may vary from language to language, it is a necessary condition that the licensing expression be downward monotonic. Consequently, the designated element can be regarded as a semantically vacuous negative polarity item.

(18) Hypothesis 2 Negative spread involves context-dependent assignment of semantic values to quantifying expressions. In particular, a universal negative within the scope of a negative is interpreted as an existential quantifier. From a semantic point of view, universal negatives can be charactenized as anti-additive. The corresponding existential quantifier belongs to the class of additive expressions.

Within a categorial framework, it is possible to build (via function composition) complex functors. Zwarts (1991) designs a calculus of monotonicity for these

\footnotetext{
${ }^{7}$ It should be noted that negarive polarity items like the ones discussed, though infinite in number (Schmerling 1971), do not nexsarily corsespond to an infinite number of disjunctive meaning functions. Without exception, the idiomatic reating of these elements involves some 'basic' verb such as 'give', 'do', 'move' etcetera in combination with a negated existential quantifier. That is to say, a productive sernantic (met-)rule (pentaps based on pragmanic principles: Fauconnier (1975)) seems to be at work that maps verb pluases containing an activity verb and an agument with the (denocational or implied) meaning 'a small bit' to the combination meaning of the hyperonym of the verb + existential quantifier, in the contexts discussed

Note that the context-sensitive meanings of NCelements and of NP idioms live in the same world, viz., of Boolean or quantificational operators. The change in verbal meaning invariantly remains in the world of sets and sopersets (that is, the operation is monotonic), and the same holds for the nominal meaning (as the existential quantifier is the top element in the hierarchy of indefinite noun plurases).

It is therefore intuitively plausible that children will be able to learn such a rule: it maps more complex verbal meanings (a specialized verb such as 'lif') onto simpler verbal meanings ('move') and complex nominal meanings ('finger') onto the simplest (Boolean) type of nominal meanings.

Incidentally, in the other type of context sensitive meaning changeFamconnier (1975) discusses, the meaning change is monownous and Boolean as well. In these cases, where noun phrases containing a superiarive denote universal quantifiers (John can solve the most difficult problems, 'John can solve every problem'), a specific noun phrase meaning is mapped onto themost general noun phrase meaning, the universal quantifier.
} 
complex functors. ${ }^{8}$ Assume that we adopt the theory of Keenan (1989), according to which subjects and all other verbal arguments and non-arguments are functors, taking verbal projections as their arguments. In doubling languages, an element that triggers doubling is a functor that looks for verbal projections marked with a negative concord feature. The role of the doubling element is to provide this feature. 9 As an illustration, reconsider the Afrikaans sentence in (2c), repeated here as (19).

$$
\begin{aligned}
& \text { Hulle het nooit gesing nie }(=2 c) \\
& \text { They have never sung not }
\end{aligned}
$$

The sentence-final element nie is analyzed as a functor that takes the past participle gesing "sung" as its argument and yields a verbal projection that is marked [+NC]. It is semantically vacuous. Downward monotonic expressions such as nooit "never" are only acceptable in Afrikaans if they combine with $[+\mathrm{NC}]$ marked projections. ${ }^{10}$ A sample derivation is given in (20):.11

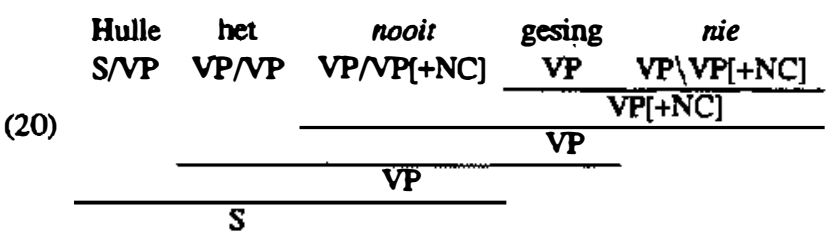

\footnotetext{
${ }^{8}$ It has been questioned (e.g. by Bill Ladusaw (P.C.)) whether the notion of context-sensitive semantics or disjunctive meaning function as used by Keenan and Pance carries over to negative concond and phenomena of that ope. It is true that the cases discussed by Keenan, Pantee and Bartsch involve only one type of function agument structure, viz. an adjective, modifying a noun, that denotes a meaning dependent on the semantics of that noun. That is to say, a functor (the modifer) is sensitive to properties of its argument (the modified element), whereas in some of the alleged NC cases it would be an argument that is sensitive to properties of a functor. The following examples, however, show the opposite picture: the adjective is taken literally, whereas the noun has a figurative, idiomatic, context dependent meaning (Verstraien 1992):

i drijvende doodkist floating coffin

"dangerous ship"

ii blonde god

blond god

"blond handsome guy"

${ }^{9}$ A suggestion along these lines may als be found in Miller (1991, 145-146): " $n$ e is assumed to be the realization of a morphosymmactic fearure triggered on the VP by the presence of the feanre [NEG,+]."

${ }^{10}$ Perhaps, the result of combiring nooit with a VP marked $[+N C]$ should be marked $[+N C]$ as well. Given phenomena such as negative tags in English, even S should "inherit" this fearure.

${ }^{11} \mathrm{~A}$ computer implementation of this theory in the framework of categorial unificarion grammar (Bouma 1993) will be described in Bouma, van der Wouden and Zwarts (in prep.).
} 
A parallel derivation may be given for the French sentence (2a), repeated here as (21):

$$
\begin{aligned}
& \text { Je n'ai vu personne } \\
& \text { I not-have seen nobody }
\end{aligned}
$$

Here, the direct object NP personne is a NP (lexically) raised to higher order: it is a functor looking for a verbal projection that is marked [+NC]. This marking is the "task" of the clitic ne, that is semantically vacuous again.

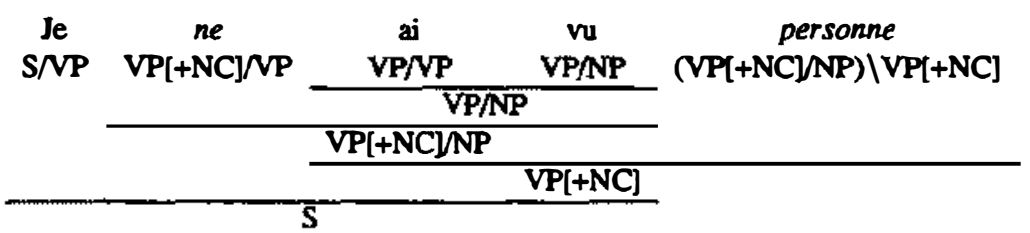

\section{Parametrizing Negative Concord}

With the help of the analytic apparatus developed so far, we are able to describe the difference between negative spread and negative doubling in terms of the elements that receive a context-sensitive semantic value. In cases of negative spread, all universal negative quantifiers within the scope of a negative quantifier shift towards existential quantifiers. In all other cases of more than one universal negative, we expect either double negation readings or ungrammaticality. In terms of the classical square of opposition, what this means is that the meaning shifts along the complement axis: ${ }^{12}$

$$
\begin{array}{ll}
\text { all }(\forall) & \text { some }(\exists) \\
\text { no }(\neg \exists \text { or } \forall \neg) & \text { not all }(\neg \forall \text { or } \exists \neg)
\end{array}
$$

A similar pattern is displayed by English quantifiers of the any-type, which can shift from a universal ("free-choice any") to an existential reading ("polarity any"), depending on the semantic properties of the context. In this case, the shift proceeds along the duality axis. ${ }^{13}$

In the case of negative doubling, on the other hand, only one designated element is polysemous in this way. The element in question is usually identical or historically related to sentence negation "not", which comes as no surprise: its meaning shifts (again, in the appropriate contexts) between negation $\neg$ and identity. ${ }^{14}$ The domain

\footnotetext{
${ }^{12}$ Perthaps the possibility of cerwin shifis and the impossibility of certain other shifts may be shown to follow from the fact that only part of De Mongan's laws holds, viz. the pan that defines downward monotonicity.

${ }^{13}$ "Dutch ooit "ever" used to behave in the same way (Stoett 1923).

${ }^{14}$ Note that the lexical element that occurs in neganive doubling is often, but not always, the same element that occurs in paratactic negation: compare French ne and English lest "that-not" below:
} 
of the meaning function of not is the set $\{1,0\}$ of truth values. As a null hypothesis, we assume that all context-sensitive meaning shifts are heavily restricted in terms of semantic types. That is, we allow a shift between the complement and identity functions, as these two meanings intuitively belong to a natural class, but not between complement and "red" or "chair" or "achieve". ${ }^{13}$ In the case at hand, this means that identity and negation are the only two non-trivial possibilities, as shown in (25):

$$
\begin{aligned}
& \{1,0\} \\
& 1 \rightarrow 1,0 \rightarrow 1 \text { trivial: all values mapped on true } \\
& 1 \rightarrow 0,0 \rightarrow 1 \text { negation } \\
& 1 \rightarrow 0,0 \rightarrow 0 \text { trivial: all values mapped on false } \\
& 1 \rightarrow 1,0 \rightarrow 0 \text { identity }
\end{aligned}
$$

We have seen that negative concord comes in two varieties: spread and doubling. Thereare, however, more degrees of freedom. For example, the operator that induces context-sensitive interpretations defines another dimension of variation. Earlier we saw that in some dialects of NC-English downward monotonic operators trigger negative spread, whereas in other variants an anti-additive expression is needed.

Furthermore, NC may be either optional or obligatory, and the notion 'in the scope of' defines yet another dimension of variation. Finally, negative spread and negative doubling may or may not occur together in a language.

There exist considerable but subtle differences between languages with respect to their negative concord behavior. Rather intricate patterns are found in the Romance languages. Ladusaw (1991), (1992) tries to account for this variation by means of parametrized well-formedness conditions on negative chains that are to be met at LF. As we have seen, however, it is not just negation that triggers NC, which means that the notion 'negative chain' cannot be taken literally. Moreover, all other things being equal, we prefer explanations that involve only surface structure over theories that need additional levels of representation. Finally, if we don't really need notions such as 'negative chain' and 'LF' for the trearment of negative and positive polarity items, we'd rather do without such constructs for the explanation of negative concord as well, as both phenomena show a lot of parallelism (cf. van der Wouden (1992)).

i Je crains qu'il ne vienne I fear that he not come-SUBJ 'I fear that he will come'

ii Then fearing lest we should have fallen upon rocks, they cast four anchors out of the stern (Acts 27:29)

\footnotetext{
${ }^{15}$ This restriction seems justified for meaning shift under the influence of logical properties of the context. It is, however, unclear whether it also holds for the other cases of context-sensitive semantics we discussed.
} 
Our present account meets these requirements and also allows for the description and explanation of many aspects of the variation found. This will be demonstrated in the next sections, where we will discuss several negative concord languages.

\section{Afrikaans}

Afrikaans ${ }^{16}$ is a pure doubling language: whenever negative words occur in a sentence, nie shows up sentence-finally. In standard Afrikaans, doubling is obligatory; in colloquial Afrikaans the reduplicator nie may be left out (as is the case with ne in spoken French).

(26) a. Ek het hom nie gesien nie I have him not seen not I have not seen him

b. Niemand het dit gesien nie Nobody has this seen not Nobody has seen this

c. Hulle het nooit gesing nie They have never sung not 'They have never sung'

Spread does not occur in Afrikaans: the occurrence of more than one negative quantifier in a sentence results in (logical) double negation.

French

Let us now take a closer look at the French data. First we demonstrate the doubling character of this language: negative subjects and objects trigger the appearance of a proclitical element ne (which is left out very often in spoken and colloquial French).

a. Personne n'a vu Jean

Nobody not-has seen John

'Nobody has seen John'

b. Jean $n$ 'a rien dit

John not has nothing seen

'John hasn't seen anything

Personne and rien are both anti-additive. On the basis of examples such as the following, however, we assume that negative doubling in French may be triggered by all downward monotonic expressions as well, both pre- and postverbally, if only they contain an overt negation: ${ }^{17}$

\footnotetext{
${ }^{16}$ Our Afrikans dara come from Ponelis (1985), den Besten (1986) and Robbers (1992).

${ }^{17}$ Note that this is exactly the characterization of the English anti-triggers, i.e. the elements that cannot be combined with positive polarity items, in Ladusew (1979).
} 
(28) a. Presque personne n'a vu Jean

Almost nobody not has seen John

'Almost nobody has seen John'

b. Je n'ai pratiquement rien vu

I not-have practically nothing seen

'I have seen practically nothing'

c. Pas plus de trois enfants $n$ 'ont lu ce livre

Not more than three children not-have read that book

Not more than three children have read that book

Following a suggestion of Hoeksema, we assume (just like Zanuttini (1991) does) that pratiquement, presque and words with a similar type of meaning may only modify universal terms. ${ }^{18}$ That is, examples such as (28) are a counterargument against the popular analysis which treats these negative elements as negative polarity items, licensed by the negative head ne.

Along the same lines, but contrary to what is commonly accepted, we analyze aucun as a negative quantifier, and not as a negative polarity item. The relevant examples are presented in (29):

a. Aucune paire de chaussures ne me va No pair of shoes not me goes

'No pair of shoes fits me'

b. Presque aucune paire de chaussures ne me va

Almost no pair of shoes not me goes

'Almost no/hardly any pair of shoes fits me'

c. Je ne connais aucun professeur dans cette université

I not know no professor in this university

'I don't know any professor in this university'

d. Je ne connais pratiquement aucun prof esseur dans cette universite I not know practically no professor in this university

'I practically don't know any professor in this university'

e. As-tu acheté des bonquets de fleurs pour maman? Non, aucun. Have-you bought of bunches of flowers for mommy? No, none. 'Have you bought any bunches of flowers for mommy? None.'

These sentences show that aucun can be modified by presque and pratiquement (which is not the case with negative polarity any), and that it can occur in isolation (which is again not the case with negative polarity any). ${ }^{19}$

\footnotetext{
${ }^{18}$ Henriette de Swart (P.C.) points out that presque may be used to modify cardinal mumbers as well: $J$ ai lu presque 500 livres "I have read almost 500 boolu" is fine. Note, however, that pratiquement cannot be used this way. The sentence $* J$ ai lu pratiquement 500 livres is ungrammatical, unless pratiquement is given sentential scope.

${ }^{19}$ Note that the Italian councerpart of aucun, alcune, is a negarive polarity itern: it doesn't occur
} 
Until now, we have been able to analyze French as the counterpart of Afrikaans: apart from differences in the placement of the reduplicator, and apart from the fact that ne always denotes the identity function, the languages behave alike. A difference, however, between the two languages is the fact that French has negative spread as well, as is demonstrated in (30):20
a. Personne n'a rien dit
Nobody not has nothing said
'Nobody has said nothing'

b. Jean n'a jamais rien dit

John not has never nothing said

'John never said anything'

c. *Jean n'a jamais dit quelque chose

John not has never something said

d. Personne n'a jamais rien dit contre toi

Nobody not has never nothing said to you

'Nobody ever said anything to you'

e. Personne ne rit plus

Nobody not laughs no-more

\footnotetext{
in isolation, nor can it be modified with quasi. That is, French personne and aucun belong, together with Italian nessuno, to the class of negarive quantifiess (with a context-sensitive semantics), and Inlian alcuncho belongs to another class, that of negative polarity items.

i Chi hai visto? Nessuno.

ii Chi hai visto? *Alcuno.

iii Non ha telefonato quasi nessuno

Not has called almost nobody

'Almost nobody called'

iv *Non ha detto quasi alcunche

Not has said almost anything

$\checkmark$ Non ha detto quasi niente

Not has said almost nothing

'He said almos nothing'

${ }^{20}$ The following sentences are the Afrikaans counterparts of the French sentences: they all have a double negation reading in standard Afrikaans:

i Niemand het nilks geseg nie $(=(30 \mathrm{a}))$

ii Jan het nooit niks geseg nie $(=(30 b))$

iii Niemand het nooit niks vir jou geseg nie $(=(30 \mathrm{~d}))$

iv Niemand lag nie meer nie $(=(30))$
} 
'Nobody laughs anymore'

These facts follow immediately from our analysis: universal negative quantifiers get an existential reading in spread environments. ${ }^{21}$ Spread virtually becomes obligatory, as altemative constructions involving existential quantifiers such as quelque chose 'something' are ruled out on the basis of the fact that they are positive polarity items (just like English some).

The asymmetry in (31) also follows from our analysis:

a. Pratiquement personne n'a rien dit

Practically nobody not has nothing said

'Practically nobody said anything'

b. *Personne n'a pratiquement rien dit $^{22}$

Nobody not has practically nothing said

Pratiquement personne in subject position creates a spread context. Pratiquement personne itself, however, is excluded from these environments: personne gets an existential meaning there, but then it may no longer be modified by pratiquement, as this element may only modify elements with a universal meaning. Note, moreover, that pratiquement personne is downward monotonic, but not anti-additive.

Note that the contrast between (29d) and (31b) is very hard to explain in theories where negation is located in ne: in either case, pratiquement is in its scope, but only if the purported negative polarity item personne is present, the sentence is out.

Moreover, this contrast is problematic for approaches such as Ladusaw's (1991, 1992) who analyzes all negative quantifiers entering in negative concord structures as indefinites. Under such an approach it should be impossible to modify these negative quantifiers with words such as presque.

From the analysis presented here, we may derive the prediction that it should be possible to use French words such as plus "more" to denote "not anymore" in certain cases, such as answers to questions. According to our informants, this prediction is borne out. A uniform analysis of the element ne predicts moreover that ne would be optional in the ne ... que construction (Dekydtspotter, this volume) as well. Again, this prediction seems to be justified by the facts (Laurent Dekydtspotter and Paul Hirschbüller, P.C.). This opens a promising perspective to an alternative analysis of this construction, in which que means "only", and ne is semantically vacuous, as usual. Discussion of the consequences of this proposal is beyond the scope of this paper.

\footnotetext{
${ }^{21}$ As we are not exactly certain on how to characterize the contexts that trigger spread, we use the descriptive term "spread environment" rather than more interesting but pertaps not completely comect terms such as "downward monotonic".

${ }^{22}$ This sentence is gramratical on a double negation reading, but that doess't concern us here.
} 
Italian

Next, consider the Italian data in (32). These are taken from Ladusaw (1991). Ladusaw (1992, fn. 10) suggests that not all native speakers of Italian will agree with all the judgements presented here.
a. Gianni non ha visto Maria John not has seen Maria 'John hasn't seen Maria'

b. Mario non ha visto nessuno Mario not has seen nobody 'Mario has seen no one'

c. Mario non ha parlato di niente con nessuno Mario not has spoken of nothing with nobody 'Mario hasn't spoken with anyone about anything'

d. Nessuno ha parlato con nessuno Nobody has spoken with nobody 'No one has spoken with anyone'

e. *Mario ha visto nessuno Mario has seen nobody

f. Nessuno ha visto Mario Nobody has seen Mario 'Nobody has seen Mario'

g. *Nessuno non ha visto Mario Nobody not has seen Mario

h. *E arrivato nessuno Is arrived nobody

i. Nessuno è arrivato Nobody is arrived 'Nobody arrived'

j. Con nessuno ha parlato nessuno With nobody has spoken nobody 'Nobody has spoken to anybody'

k. *Con nessuno non ha parlato nessuno With nobody not has spoken nobody

1. Non ha telefonato nessuno Not has telephoned nobody 'nobody called'

We observe that preverbal negative quantifiers never co-occur with non, except under a double negation reading ( $a$ s in ( $32 \mathrm{k}$ )), and that postverbal negative quantifiers always co-occur with non, unless some negative quantifier occurs preverbally, in which case non is forbidden. 
Within our theory, we account for the Italian facts in the following way. Assume that negative spread occurs freely in Italian (e.g. (32d)), that is, the meaning of a negative quantifier shifts, in the appropriate contexts, from a universal negative to an existential. Moreover, doubling occurs as well, but only from right to left. ${ }^{23} \mathrm{I} . e$. ., only postverbal quantifers trigger doubling.

The difference between (32c), where doubling is obligatory, and (32j), where it is forbidden on the concord reading, then follows. In (32c) niente, being a postverbal quantifier, triggers doubling to its left. On the other hand, it also triggers an existential reading of nessuno to its right. In (32j) the preverbal nessuno triggers the existential reading for its postverbal counterpart. But existential quantifiers are never able to trigger doubling. Then, the only interpretation available for non is negation, $\neg$, i.e., if the sentence is interpretable at all, it is under a double negation reading: "with nobody not has spoken anybody".

Catalan

Next, consider the Catalan data in (33) (again taken from Ladusaw (1991)): ${ }^{24}$

(33) a. En Pere no ha fet res The Peter not has done nothing

'Peter has done nothing'

b. *En Pere ha fet res

The Peter has done nothing

c. No m'ha telefonat ningu

Not me-has telephoned nobody

'nobody has called me'

d. *M'ha telefonat ningr

Me-has telephoned nobody

e. Ningu (no) ha vist en Joan

Nobody (not) has seen the John

'nobody has seen John'

According to Jaume Sola (P.C.), the bracketing of no in the last example should not be interpreted as optionality of doubling, but as referring to dialectal variation. That is, there exists one dialect of Catalan that parallels French (or Afrikanns) in the

\footnotetext{
${ }^{23}$ This may be implemented in a categorial grammer by making all negetive quantifiers ambiguous berween S/VP (in preverbal position) and $S \backslash V[+N C]$, i.e., it is either a rightward looking functor looking for a verb phrase, or a leftwand looking funcorr looking for a $[+\mathrm{NC}]$ marked vert. One of the categories of non will then be VDNCWV, i.e. a functor that takes a verb and yields a $[+\mathrm{NC}]$ marked verb. Identity is the meaning function associated with this category (and only with this category). Pertaps we find this kind of arymmeory only in so-called pro-drop languages. Then we would have a syntactic or semantic rationale for the difference in category for pre- and postvertal subject quantifiers: preverbal subjects are real subjects, whereas postvertal subjects "double" the (phonologically null) subject without actually fulfilling the subject function.

${ }^{24}$ Thanks to Jaume Sola for discussing the Camalan dam with us.
} 
sense that a doubling element no (that may express negation on its own) is always obligatory whenever negative elements show up in the sentence, and another dialect that behaves like Italian, with doubling only from postverbal positions.

To sum up this section

We have discussed some of the variants of negative concord discussed in the literature. They all seem to fit nicely in our theory. The results are presented in the table in (34):

\begin{tabular}{|c|c|c|c|c|}
\hline language & type & placement & $\begin{array}{l}\text { directionality } \\
\text { of doubling }\end{array}$ & remarks \\
\hline Afrikaans & doubling & sentence final & from left & $\begin{array}{l}\text { nie ambiguous: } \\
\neg \text { or id }\end{array}$ \\
\hline $\begin{array}{l}\text { French } \\
\text { Italian }\end{array}$ & $\begin{array}{l}\text { spread \& doubl. } \\
\text { spread \& doubl. }\end{array}$ & $\begin{array}{l}\text { clitic to verb } \\
\text { clitic to verb }\end{array}$ & $\begin{array}{l}\text { left and right. } \\
\text { from right }\end{array}$ & $\begin{array}{l}\text { ne always id } \\
\text { non ambiguous: } \\
\neg \text { or id }\end{array}$ \\
\hline Catalan & spread \& doubl. & clitic to verb & & $\begin{array}{l}\text { two variants: } \\
\text { one like French, } \\
\text { one like Italian }\end{array}$ \\
\hline
\end{tabular}

Note that spread always proceeds from left to right.

\section{Concluding Remarks}

In the above, we have sketched a semantic theory of negative concord. We have argued that one should distinguish between negative spread, which involves contextsensitive meanings of elements that look like universal negative quantifiers, and negative doubling, where verbal projections are obligatorily marked in a special way by a designated element. In the latter case, the [+NC] marked projection must be licensed by a negative element of the appropriate type.

Given this approach, a fundamental difference between negative doubling and negative polarity presents itself. Negative doubling involves a bi-directional dependency between a negative quantifier and the reduplicator. In negative polarity structures, on the other hand, the polarity item is only dependent on the semantic properties of the context. That is to say, the element that projects the relevant semantic properties onto the context is not in any sense dependent on the polarity item.

\section{References}

Atkins, B. T., Kegl, J. and Levin, B.: 1988, Anatomy of a verb entry: from linguistic theory to lexicographic practice, International Journal of Lexicography 1, 84-126. 
Bouma, G.: 1993, Nonmonotonicity and Categorial Unification Grammar, PhD thesis, Groningen.

den Besten, H.: 1986, Double negation and the genesis of Afrikaans, in P. Muysken and N. Smith (eds), Substrata versus Universals in Creole Languages. Papers from the Amsterdam Creole Workshop, April 1985, Benjamins, Amsterdam/Philadelphia, pp. 185-230.

Bouma, G., van der Wouden, T. and Zwarts, F: in prep., A constraint-based approach to negative concord, Ms. BCN, Groningen.

Dowty, D. R.: 1979, Word Meaning and Montague Grammar, Reidel, Dondrecht.

Fauconnier, G.: 1975, Polarity and the scale principle, CLS, Vol. 11, Chicago Linguistic Society, pp. 188-199.

Haegeman, L. and Zanuttini, R.: 1990, Negative concord in west flemish, Unpublished Ms., to appear in A. Belletti and L. Rizri (eds.), Parameters and Functional Heads.

Hoeksema, J.: 1983, Negative polarity and the comparative, Natural Language and Linguistic Theory 1, 403-434.

Keenan, E. L.: 1974, The functional principle: Generalizing the notion of 'subject-of', Papers from the Tenth Regional Meeting of the Chicago Linguistics Society, Chicago, Illinois, pp. 298-310.

Keenan, E. L.: 1989, Semantic case theory, in R. Barsch, J. van Benthem and P. van Embde Boas (eds), Semantics and Contertual Expression, Foris, Dordrecht [etc.], pp. 33-56.

Labov, W.: 1979, Negative attraction and negative concond, in W. Labov (ed.), Language in the Inner City. Studies in the Black English Vernacular, Basil Blackwell, Oxford. First published as "Negative Auraction and Negative Concord in English grammar" in Language 48, 1972, 773-818.

Ladusaw, W. A.: 1979, Polarity Sensitivity as Inherent Scope Relations, PhD thesis, University of Texas at Austin. Distributed by IULC, Bloomington, Indiana, 1980. Also published by Garland Press: Outstanding Dissertations in Linguistics, New York.

Ladusaw, W. A.: 1991, Interpreting negative concord structures, Paper read at the 1991 LSA Annual Meeting.

Ladusaw, W. A.: 1992, Expressing negation, in C. Barker and D. Dowty (eds), Proceedings of the Second Conference on Semantics and Linguistic Theory, Vol. 40 of Ohio State Working Papers in Linguistics, The Ohio State University, Columbus, pp. 237-259.

Miller, P. H.: 1991, Clitics and Constituents in Phrase Structure Grammar, PhD thesis, Utrecht. 
Napoli, D. J. and Nespor, M.: 1976, Negatives in comparatives, Language 52,4, 811-838.

Partee, B. H.: 1984, Compositionality, in F. Landman and F. Velman (eds), Varieties of Formal Semantics. Proceedings of the fourth Amsterdam Colloquium, September 1982, Vol. 3 of GRASS, Foris, Dordrecht, pp. 281-311.

Ponelis, F.: 1985, Afrikaense Sintaksis, JL. v an Schaik, Pretoria. Tweede druk.

Pustejovsky, J.: 1989, Current issues in computational lexical semantics, Fourth Conference of the European Chapter of the Associationfor Computational Linguistics.

Robbers, K.: 1992, Properties of negation in Afrikaans and Italian, in R. Bok-Bennema and R. van Hout (eds), Linguistics in the Netherlands 1992, Benjamins, Amstendam/Philadelphia, pp. 223-234.

Schmerling, S.: 1971, A note on negative polarity, Papers in Linguistics 4(1), 200-206.

Seuren, P. A.: 1991, Grammatika als algorithme: rekenen met taal, Koninklijke Nederlandse Akademie van Wetenschappen, Mededelingen van de Afdeling Letterkunde, Nieuwe Reeks.

Swett, F.: 1923, Middelnederlandsche Spraaklanst. Syntaris, Martinus Nijhoff, 's-Gravenhage. Dende herziene dnuk, vijfde oplage, 1977.

Talmy, L.: 1985, Lexicalization pattems, in T. Shopen (ed.), Language Typology and Syntactic Description, Cambridge University Press, Cambridge.

Verstraten, L.: 1992, Vaste verbindingen. Een lericologische studie vanuit cognitief-semantisch perspectief naar fraseologismen in het Nederlands, PhD thesis, Leiden.

van der Wouden, T.: 1992, Polarity and 'illogical negation', Ms. Groningen.

van der Wouden, T. and Zwarts, F: 1992, Negative concond, in D. Gilbers and S. Looyenga (eds), Language and Cognition 2. Yearbook 1992 of the research group for Linguistic Theory and Knowledge Representation of the University of Groningen. TENK, Groningen, pp. 317-331.

Zanutuini, R: 1991, Syntactic Properties of Sentential Negation. A Comparative Study of Romance Languages, PhD thesis, University of Pennsylvaria.

Zwarts, F.: 1981, Negatief polaire uitdrukkingen 1, Glot 4, 35-132.

Zwarts, F.: 1991, Negation and generalized quantifiers, in J. van der Does and J. van Eijck (eds), Generalized Quantifier Theory and Applications, Dutch Network for Language, Logic and Information, Amsterdam, pp. 443-462.

Ton van der Wouden and Frans Zwarts

BCN, University of Groningen

PO Box 716, 9700 AS Groningen, The Netherlands

vdwouden@let.nug.nl, frans@let.ng.nl 